\begin{tabular}{|c|c|c|}
\hline \begin{tabular}{|c|} 
EQE 830 \\
pp: $1-16$ (col.fig.: Nil)
\end{tabular} & PROD. TYPE: COM & \begin{tabular}{|c|} 
ED: Bhavani \\
PAGN: J.Lakshmi - SCAN:
\end{tabular} \\
\hline
\end{tabular}

EARTHQUAKE ENGINEERING AND STRUCTURAL DYNAMICS

Earthquake Engng Struct. Dyn. (2008)

Published online in Wiley InterScience (www.interscience.wiley.com). DOI: 10.1002/eqe.830

\title{
Performance of a damage-protected beam-column subassembly utilizing external HF2V energy dissipation devices
}

\section{Geoffrey Rodgers ${ }^{1, *, \dagger}$, Kevin M. Solberg ${ }^{2}$, J. Geoffrey Chase ${ }^{1}$, John B. Mander ${ }^{3}$,}

${ }^{1}$ Department of Mechanical Engineering, University of Canterbury, Private Bag 4800, Christchurch 8140, New Zealand

Department of Civil Engineering, University of Canterbury, Private Bag 4800, Christchurch 8140, New Zealand

${ }^{3}$ Zachry Department of Civil Engineering, Texas A\&M University, College Station, TX 77480, U.S.A.

\section{SUMMARY}

11 Ductile-jointed connections, which generally require some form of supplementary energy dissipation to alleviate displacement response, typically employ mild steel energy dissipation devices. These devices run

13 the risk of low-cycle fatigue, are effective only for peak cycles that exceed prior displacements, are prone to buckling, and may require replacement following an earthquake. This study presents an experimental 15 investigation employing an alternative to mild steel: a high force-to-volume (HF2V) class of damper-based energy dissipation devices. Tests are performed on a near full-scale beam-column joint subassembly 17 utilizing externally mounted compact HF2V devices. Two configurations are considered: an exterior joint with two seismic beams and one gravity beam framing into a central column, and a corner joint with 19 only one seismic beam and one gravity beam framing into a column. Quasi-static tests are performed to column drifts up to $4 \%$. The experiments validate the efficacy of the HF2V device concept, demonstrating

21 good hysteretic energy dissipation, and minimal residual device force, allowing ready re-centring of the joint. The devices dissipate energy consistently on every cycle without the deterioration observed in the

23 yielding steel bar type of devices. The effectiveness of the HF2V devices on structural hysteretic behavior is noted to be sensitive to the relative stiffness of the anchoring elements, indicating that better efficiency

25 would be obtained in an embedded design. Copyright (C) 2008 John Wiley \& Sons, Ltd.

Received 31 January 2008; Revised 17 April 2008; Accepted 1 May 2008

KEY WORDS: high force-to-volume (HF2V) damper; energy dissipation; damage-avoidance design; post-tensioned connection; jointed precast connection; extrusion damping

\footnotetext{
*Correspondence to: Geoffrey Rodgers, Department of Mechanical Engineering, University of Canterbury, Private Bag 4800, Christchurch 8140, New Zealand.

†E-mail: gwr37@student.canterbury.ac.nz
} 


\section{EQE 830}

Research and development of precast concrete jointed and rocking structures has gained considerable momentum over the past two decades, with significant research on the so-called PRESSS systems [1], damage-avoidance design (DAD) [2-4] in the Unites States and New Zealand [5-7].

5 These systems, designed to accommodate inelastic behaviour by rocking at specially detailed joints, have proven to provide a level of seismic resistance comparable to current standards while

7 remaining almost (in the case of PRESSS) or essentially (in the case of DAD) damage-free. Furthermore, such systems do not suffer excessive residual displacement, a common occurrence in conventional sacrificially designed systems, which often leads to complete loss of the structure.

Precast jointed and rocking systems exhibit non-linear response by connection opening instead 11 of the conventional sacrificial, energy dissipating, formation of a plastic hinge. As a result, they have markedly less inherent energy dissipation than ductile monolithic systems $[8,9]$. Therefore,

13 it is desirable to provide supplemental energy dissipation devices to these connections to reduce displacement response from earthquakes.

15 An early application presented by Stanton et al. [10] utilized mild steel rods running across the connection and grouted in ducts, which were designed to yield in tension and compression.

17 Although test results revealed satisfactory hysteretic energy dissipation, because the bond between the grout and steel deteriorated, some stiffness and strength degradation was observed. In addition,

19 repeated cycles led to bar fracture in some tests due to low-cycle fatigue, showing an inherent weakness in any sacrificial yielding-steel energy dissipation approach, be it a device or by sacrificial design.

Subsequent research has highlighted alternative mild steel energy dissipation devices, bolted externally across the joint region. Bradley et al. [5] have demonstrated that externally mounted steel yielding devices can provide a stable hysteric performance with negligible stiffness or strength

25 degradation. However, due to low-cycle fatigue and residual stresses these devices would still have to be replaced following an earthquake. In addition, they only offer repeated peak dissi-

27 pation when they yielded further than a previous cycle. Subsequent smaller cycles, the bulk of an earthquake input, thus receive minimal or no dissipation. The work of Bradley et al. [5] also

29 demonstrated that their steel yielding devices were prone to buckle, thereby reducing the axial load and energy dissipation capacities [11]. Amaris et al. [12] demonstrated that with externally

31 mounted buckling-restrained mild steel bars, slightly improved performance may be obtained; however, their system retained the same fatigue-prone and residual force deficiencies as in Bradley

33 et al. [5].

It then becomes apparent that a more robust form of energy dissipation is needed that satisfies 35 several objectives: (i) energy dissipators should not be at risk of low-cycle fatigue bar fracture; (ii) energy dissipators should be ideally located within the beam-column joint region; (iii) to

37 ensure that the structure re-centres, residual forces in the energy dissipator should either re-centre or creep back towards zero over time; and (iv) the cost of devices should be economical compared with conventional (ductile) design solutions.

In response to these objectives, a high force-to-volume (HF2V) lead-extrusion damper was 41 developed $[13,14]$. The HF2V damper is a relatively simple device, as illustrated in Figure 1. It consists of a central shaft with a bulge encased in lead. When the shaft moves, the bulge displaces 43 the lead from one side of the bulge to the other and is capable of sustaining a constant force upon yielding, similar to the behaviour of the mild steel energy dissipation devices. These devices have been shown to be relatively insensitive to velocity [14], with a relationship between damper force 


\section{EQE 830}

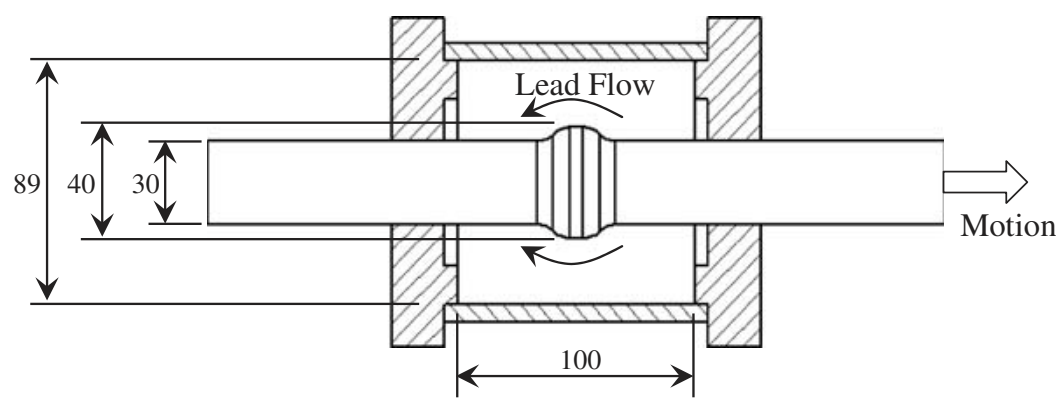

Figure 1. Cross-section of a typical HF2V damper (dimensions in $\mathrm{mm}$ ).

1 and velocity defined:

$$
F=C_{\alpha} v^{\alpha}
$$

3 where $F$ is the damper force; $C_{\alpha}$ a constant dependent on device architecture; $v$ the velocity of the shaft; and $\alpha$ the velocity component, which can be taken as $0.12[13,14]$.

5 The compact HF2V devices are based on the original lead-extrusion dampers developed by Robinson and Greenbank [15]. These early devices were quite large (1-2 m long for $100+\mathrm{kN}$

7 capacity), limiting their use to specific applications such as base isolation [16]. In contrast, the unique aspect of the HF2V devices is their ability to fit into tight volumetrically constrained

9 applications, such as directly into beam-column joints $[13,14]$. More specifically, $100-350 \mathrm{kN}$ devices have been built that are $120 \mathrm{~mm}$ long, with a $100 \mathrm{~mm}$ outside diameter of the confining

11 cylinder, considerably smaller than other devices of similar capacity [13].

In this study, two HF2V devices were designed and fabricated to be mounted on external anchor

13 plates protruding from each side of the beams. The experimental testing is intended to confirm the benefits of such devices when incorporated into ductile-jointed connections. In addition, results

15 can be compared with the spectral analyses and design guideline predictions developed for these devices [13,14].

\section{DESIGN DETAILS}

\section{Subassembly development}

19 A 3D subassembly representing an exterior joint on a lower floor of a 10-storey prototype building was developed as shown in Figure 2. The subassembly consisted of two beams cut at their midpoints

21 and an orthogonal beam cut at its midpoint, the approximate location of the point of contraflexure. All of these members frame into a central column. The orthogonal beam, referred to as the gravity

23 beam, was designed for supporting one-way precast flooring panels. The other two beams, referred to as the seismic beams, were designed for predominantly seismic forces. The dimensions of the 25 prototype members were taken from previous research [17]. Specific dimensions include: $850 \mathrm{~mm}$ square columns, $700 \mathrm{~mm}$ deep by $500 \mathrm{~mm}$ wide beams, and a $3.6 \mathrm{~m}$ storey height. The prototype

27 joint was assumed to have a moment capacity of $500 \mathrm{kNm}$.

Given these constraints, the subassembly was scaled to $80 \%$ of the prototype building. The 29 column was scaled to $750 \mathrm{~mm}$ square and the beams scaled to $560 \mathrm{~mm}$ deep by $400 \mathrm{~mm}$ wide. 


\section{EQE 830}

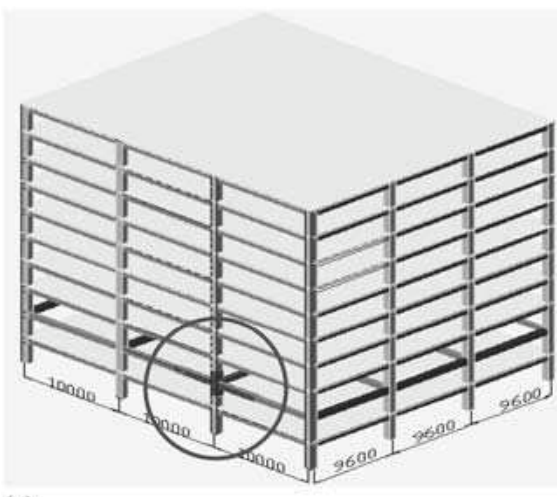

(a)

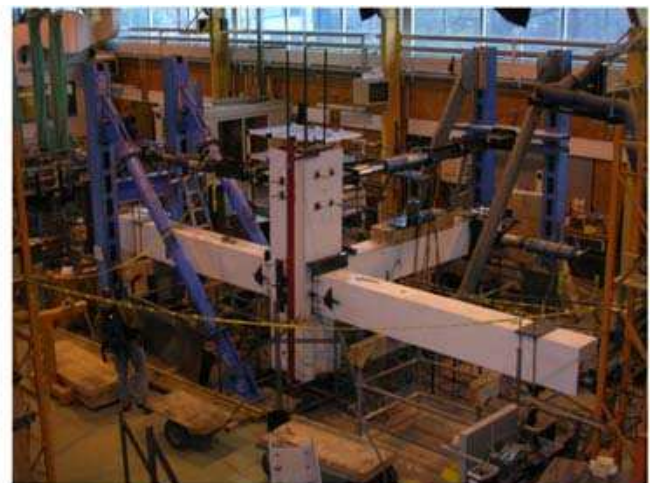

(b)

Figure 2. (a) Prototype structure showing location of subassembly [17] and (b) photograph of experimental set-up.

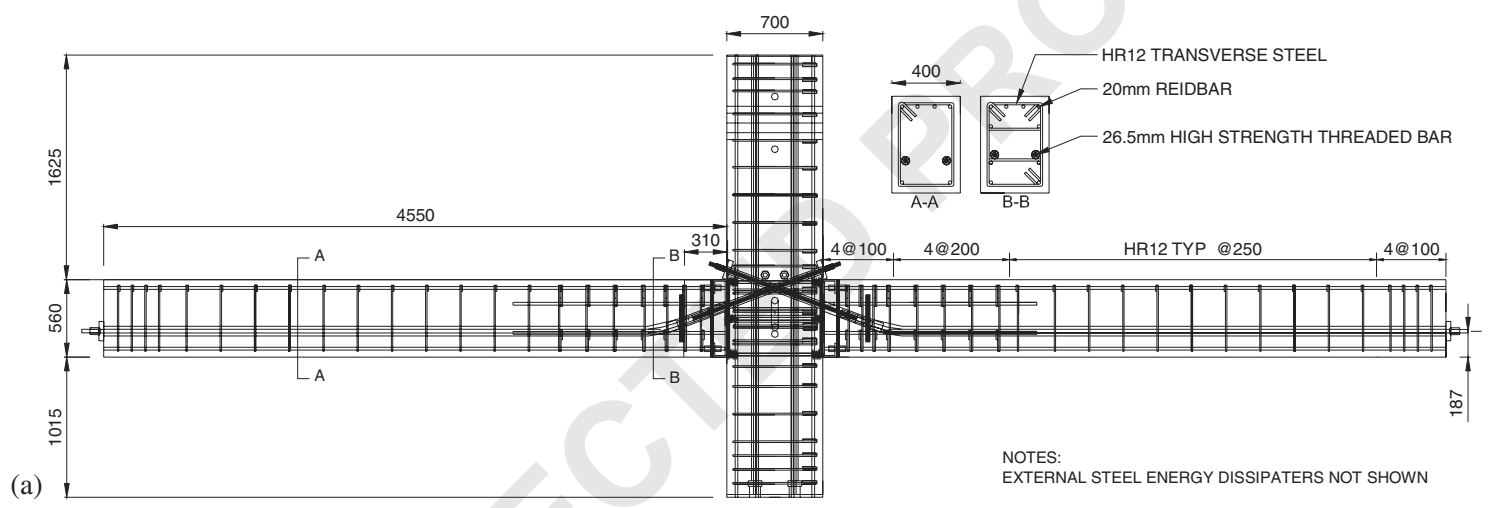

(b)

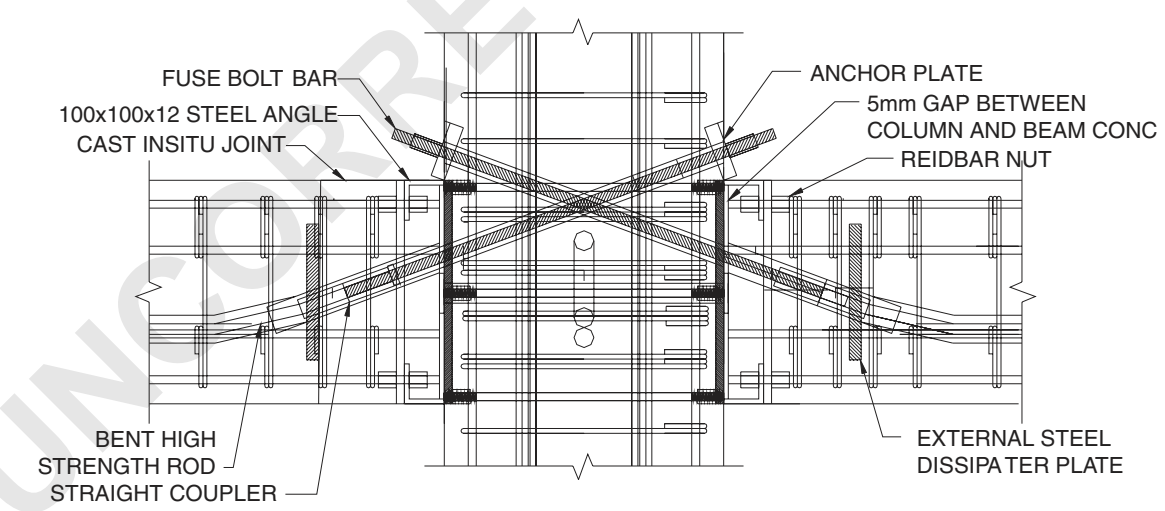

Figure 3. (a) Elevation of the seismic beams and column and (b) details of the seismic beam-column joint experimental subassembly.

1 Figure 3(a) shows the seismic beams, column and basic dimensions. Minimal longitudinal reinforcement (ratio of 0.01) was provided for the column and the beams. Figure 3(b) illustrates the 3 basic reinforcing layout for the beams and the column. 


\section{EQE 830}

PERFORMANCE OF A DAMAGE-PROTECTED BEAM-COLUMN SUBASSEMBLY

The reinforcement arrangements were designed for the expected strength of the rocking joint from the dissipation devices and prestressing and were intended to remain elastic. Four

3 D20 longitudinal threaded rebars (Reidbar ${ }^{\mathrm{TM}}, f_{y}=500 \mathrm{MPa}$ ) were provided top and bottom, providing the required moment capacity of $\phi M_{n}=260 \mathrm{kNm}$. Owing to the presence of axial load

5 from prestress, minimal transverse steel requirements governed the design; thus $12 \mathrm{~mm}$ diameter (HR12, $f_{y}=500 \mathrm{MPa}$ ) stirrups were provided in the beam at a spacing of $d / 2$ and a closer spacing

7 at the ends. Additional transverse reinforcement was provided at the top and bottom, $1.2 \mathrm{~m}$ from the beam ends, to confine the concrete in these high-compression zones.

9 Unbonded post-tensioned prestressing was provided by two $26.5 \mathrm{~mm}$ diameter high-strength thread bars placed in $50 \mathrm{~mm}$ PVC ducts, each post-tensioned to $200 \mathrm{kN}$, giving $400 \mathrm{kN}$ of total

11 prestress to each seismic beam, as illustrated in Figure 3(b). A detailed diagram of the seismic beam-column joint is given in Figure 3(b). The 'seismic' beams utilized a straight coupler system

13 where the tendons were pre-bent at the joint end to a radius of approximately $1.8 \mathrm{~m}$, allowing proper alignment with the angled rod running through the column. The fuse bolt bar was machined

15 to $75 \%$ of its effective area to ensure that any yielding in the prestress system would be limited to the replaceable through-column bolt bar. The tendon detailing resulted in an eccentricity of

$17190 \mathrm{~mm}$ from the top rocking edge and $370 \mathrm{~mm}$ from the bottom rocking edge. At the beam end, a $100 \times 100 \times 12$ inverted steel angle was used at the top and bottom of the joint and the face

19 of concrete was recessed $5 \mathrm{~mm}$. This design ensured that contact with the column was limited to the steel and allowed the angle's buried flange to mechanically develop stress in the beam's

21 longitudinal rebars using Reidbar ${ }^{\mathrm{TM}}$ nuts.

By the nature of precast concrete and rocking connections, it is critical that the face of the beam

23 be aligned flush with the column. Therefore, offsite erection of a full length beam section may lead to on-site misalignment issues, which may affect rocking behaviour. To mitigate potential

25 misalignment and also to allow for construction tolerances similar to current standards, a $310 \mathrm{~mm}$ cast in situ closure pour was provided on the west seismic beam. Such a closure pour is expected

27 to be cast on-site after the armouring angles have been adjusted to ensure a flush face at both ends and the post-tensioning rods are coupled together.

High-strength, fibre-reinforced concrete using $2 \%$ Dramix $^{\mathrm{TM}}$ steel fibres by weight was used in the in situ end to compare its behaviour with the regular strength concrete of the east beam.

31 The mix was designed for high strength and good workability. The measured compressive cylinder strength of the high-strength concrete was $f_{\mathrm{c}}^{\prime}=70 \mathrm{MPa}$, whereas the east beam and the remainder of the west beam concrete was measured as $f_{\mathrm{c}}^{\prime}=37 \mathrm{MPa}$.

At each joint, four $30 \mathrm{~mm}$ diameter shear keys were installed, tapered $5^{\circ}$ inwards to ensure that

35 they do not jam when the specimen rocks at the beam-column joint. These were designed to be screwed into the face of the column via a cast in double nut. The shear keys were designed to resist

37 gravity and seismic shear forces. One shear key was located in each corner, providing torsional resistance.

\section{The HF2V devices}

HF2V devices were designed to be mounted externally on purpose-built plates in the beams. An 41 assembly of the HF2V dampers is given in Figure 4. Device design and characterization details can be found in Rodgers et al. [13,14]. A central shaft with a streamlined bulge was encased in

43 a cylinder filled with lead. Rectangular end caps were bolted together via two attachment rods, which also anchored the device to the beam's anchor plate. One end of the central shaft was 


\section{EQE 830}
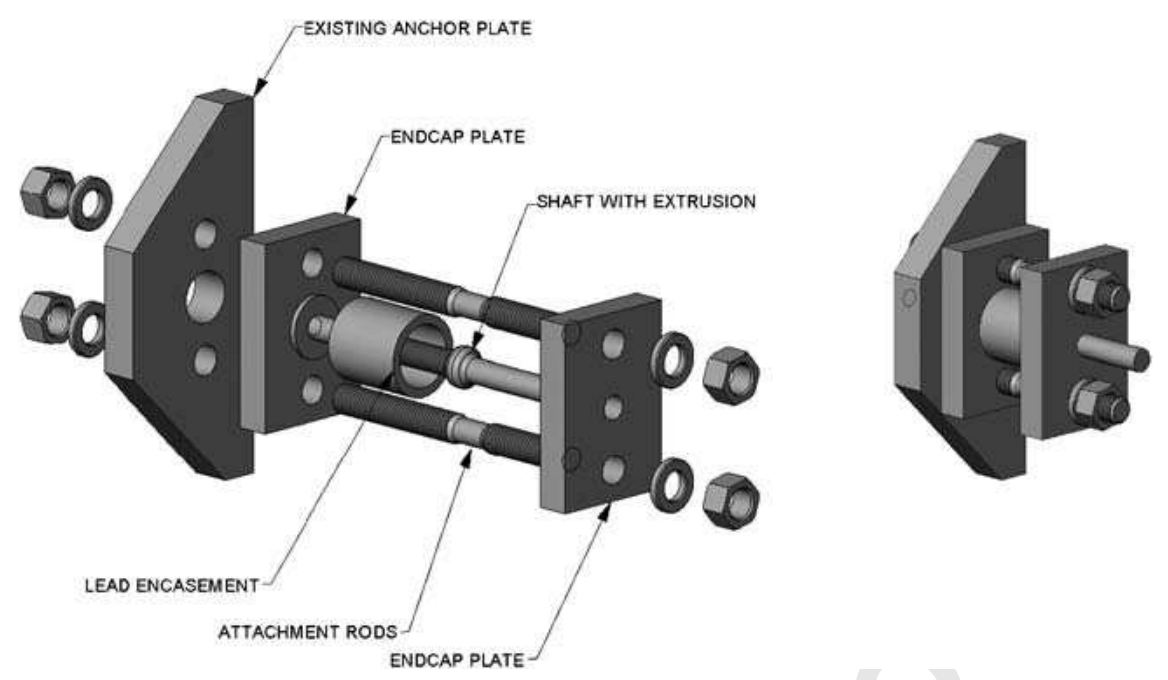

Figure 4. The HF2V damper externally mounted on the beam's anchor plate.

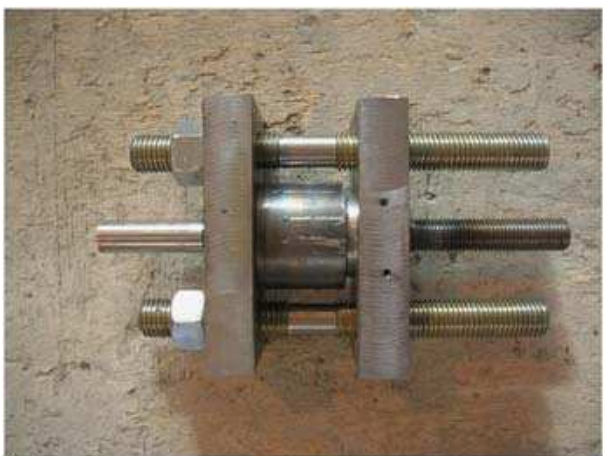

(a)

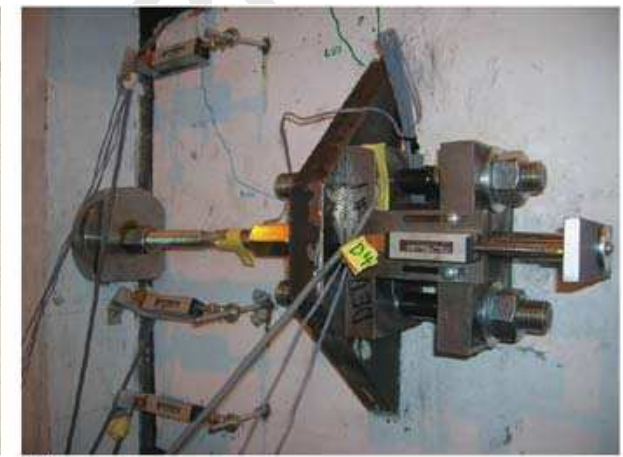

(b)

Figure 5. Photographs of the external HF2V damper: (a) prior to installation and (b) mounted on the east beam.

1 threaded, allowing it to be coupled to a threaded rod anchored to the column. The threaded rod running through the column was anchored on each end of the column face using a nut and steel

3 plate washer. A photograph of the device and the mounting configuration is given in Figures 5(a) and (b), respectively. The force capacity of these devices is $125-130 \mathrm{kN}$.

5 Device force capacity affects the mechanics and behaviour of the joint. More specifically, to ensure that the connection is capable of closing, the moment contribution from the initial prestress

7 force must exceed the contribution from the dampers. This criterion can be written as follows:

$$
\phi M_{\mathrm{PS}, i} \geqslant \Omega_{\mathrm{diss}} M_{\mathrm{diss}}
$$

9 where $M_{\mathrm{PS}, i}$ is the moment contribution at the joint from the initial prestress force; $M_{\text {diss }}$ the moment contribution at the joint from the energy dissipation devices in compression; $\Omega_{\text {diss }}$ the over-

11 strength factor of the dissipation devices (taken as 1.5); $\phi$ the undercapacity factor for the prestress 


\section{EQE 830}

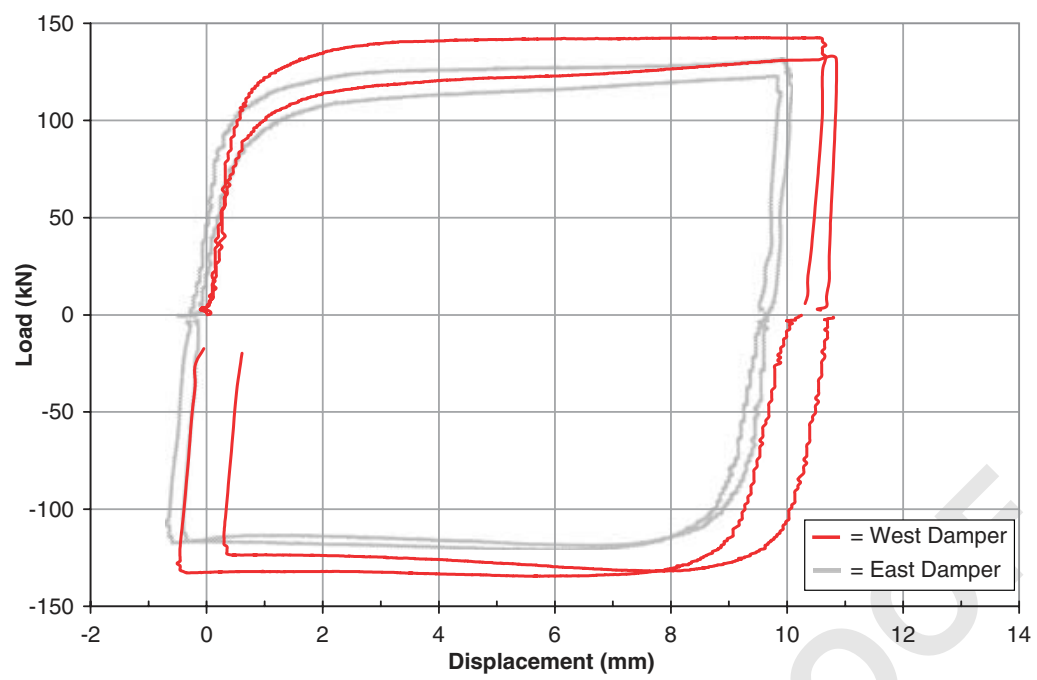

Figure 6. Force-displacement response of the HF2V dampers prior to testing.

1 (taken as 0.85). Dividing the contribution from prestress by the contribution from the dissipation devices gives a ratio of their expected contribution:

$$
\lambda=\frac{\phi M_{\mathrm{PS}, i}}{\Omega_{\mathrm{diss}} M_{\mathrm{diss}}}
$$

To ensure that the system re-centres, $\lambda \geqslant 1$ must hold true. The dampers were therefore specifically designed [13] to provide the same level of energy dissipation as mild steel devices adopted by Li et al. [17], corresponding to a designed $120 \mathrm{kN}$ yield force. This design force corresponds to

$7 \lambda=1.3$ and 2.5 in the east-west direction for positive and negative moments, respectively, which reflects the eccentricity of the tendons at the joint. As two seismic beams meet at the one column,

9 the overall joint is symmetrical as the eccentricity of the tendon profile is counteracted when the opposing beam is opening in the opposite direction, giving a ratio of $\lambda=1.9$.

11 To validate the as-built devices, reversed cyclic quasi-static (QS) tests were performed on the HF2V dampers using a uni-axial compression-tension testing machine. The experimental force-

13 displacement response of the dampers subjected to these tests is shown in Figure 6. The devices exhibit a clear elasto-plastic hysteretic behaviour, with an average initial stiffness of $200 \mathrm{kN} / \mathrm{mm}$.

15 The average force capacity is at the design level, with forces of $120-130 \mathrm{kN}$.

\section{EXPERIMENTAL SET-UP AND METHODS}

17 Figure 7 shows the overall experimental test set-up including (a) a plan view and (b) a south elevation view. As shown in Figure 7, loads were applied to the specimen by three hydraulic

19 actuators: actuators A and B were installed on the reaction frame and top of the east and south face of the column, respectively, and actuator $\mathrm{C}$ was installed in the east-west direction at the

21 end of the gravity beam. Actuator $\mathrm{C}$ was intended to stabilize the specimen, with its movement synchronized to one-half of the displacement of actuator A. Load cells were installed in series 


\section{EQE 830}

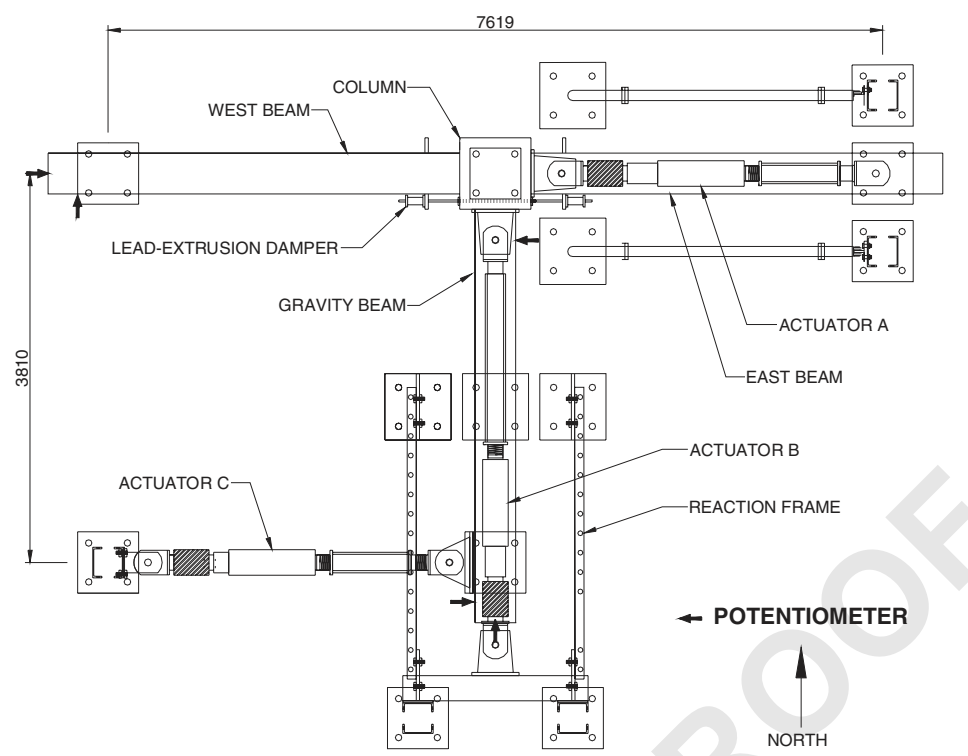

PLAN VIEW

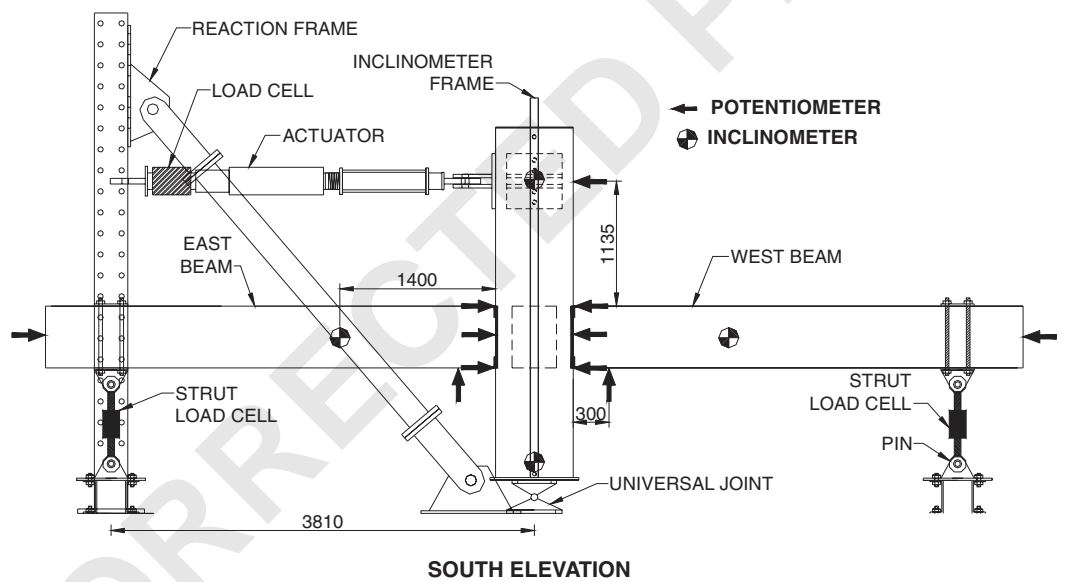

Figure 7. Schematic diagrams of the test set-up and instrumentation.

1 with each actuator. Additional load cells were attached at the strut of each beam, the jacking point of each post-tensioned rod, and on the connecting rods to the HF2V devices.

3 To measure the rotation at the joint, three linear potentiometers were installed on both faces of each joint, totalling 18 potentiometers. Two additional linear potentiometers were installed against

5 the bottom face of each beam to measure vertical movement. At several locations around the specimen rotary potentiometers were installed to measure the local displacement. Two $5 \mathrm{~mm}$ strain

7 gauges were installed on each bolt bar to measure any potential yielding that may occur during testing. To measure the response of the HF2V dampers, a load cell and strain gauges were attached

9 to the anchor rod of each device. A spring potentiometer was mounted on the back of each device to measure the displacement of its central shaft. 


\section{EQE 830}

PERFORMANCE OF A DAMAGE-PROTECTED BEAM-COLUMN SUBASSEMBLY

The instrumentation was installed and calibrated to use $70-85 \%$ of the total sensor range during testing to $4 \%$ column drift. Using data acquisition with \pm 2048 counts, this approach gave

3 approximately $3000-3500$ counts for $4 \%$ drift, giving a resolution of approximately $\pm 0.1 \mathrm{kN}$ on the actuator load cells, $\pm 0.05 \mathrm{kN}$ on the device load cells, $\pm 0.15 \mathrm{~mm}$ on the large rotary potentiometers,

5 and a theoretical resolution of approximately $10 \mu \mathrm{m}$ on the smaller linear potentiometers. The control system operated with a typical deadband of 1 count, equating to $\pm 0.15 \mathrm{~mm}$ on the lateral

7 column displacement.

The testing regime was relatively straightforward and focused entirely on the performance of

9 the HF2V dampers for different design levels of storey drift. Cyclic QS tests were performed at varying levels of storey drift. These tests were uni-directional in the east-west direction. The

11 north-south direction is largely disregarded in this investigation, since its performance has already been reported in previous studies $[5,18]$. The testing was conducted in two phases, initially using a

13 single damper attached to the south side of each seismic beam. The second phase involved removing the east beam and both dampers were placed on the west beam, thus doubling its damping capacity

15 (giving re-centring ratios $\lambda^{+}=0.65 ; \lambda^{-}=1.25$ ). The second configuration represents a corner joint of the prototype building.

\section{EXPERIMENTAL RESULTS}

\section{Exterior joint}

19 Experimental results from this section focus on the global performance of the specimen and the local performance of the HF2V dampers. Since the local behaviour of the specimen (i.e. cracking,

21 crushing, prestress, etc.) has been reported previously [5, 18], these aspects of the results are not reported here.

23 For purposes of comparison, Figure 8 presents the results of QS testing in the east-west direction to a maximum column drift of $2 \%$ for three cases: (i) prestress only; (ii) mild steel energy dissipators; and (iii) the HF2V devices.
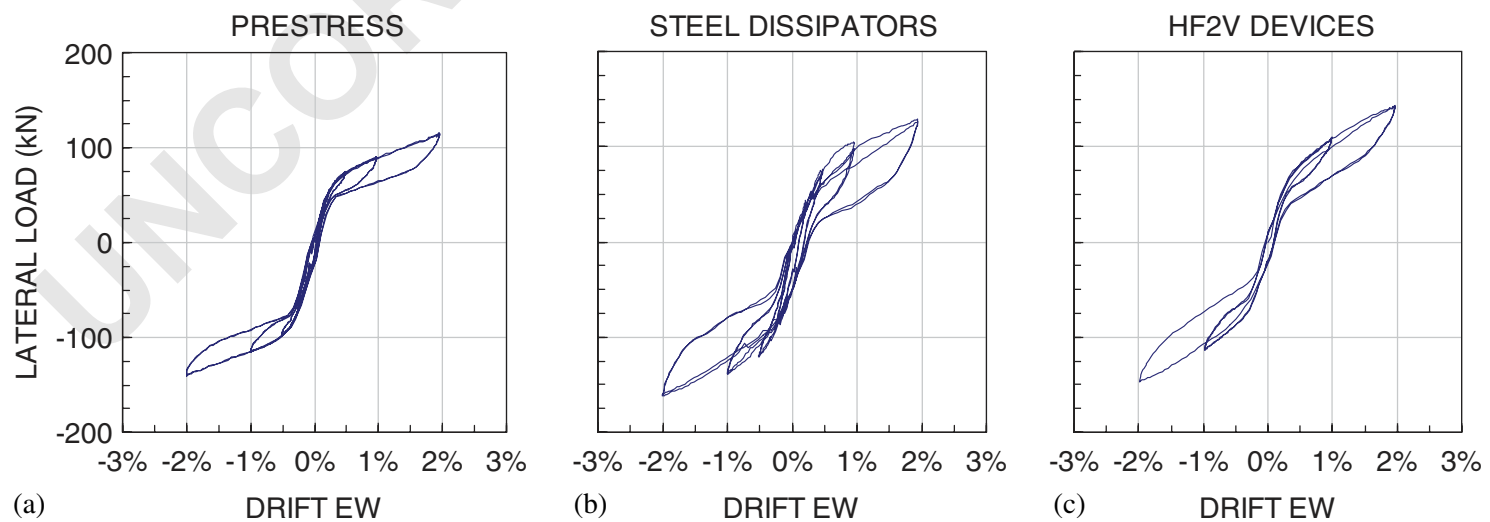

Figure 8. Comparison of the performance considering: (a) prestress only;

(b) steel dissipators; and (c) HF2V devices. 


\section{EQE 830}

10

G. RODGERS ET AL.

With prestress only, it is apparent that the system still provides some level of energy dissipation, largely due to the frictional effects under movement reversal arising from the draped and bent

3 thread bars within the ducts. The steel devices provide the most hysteretic energy dissipation for these small drift cycles, and the HF2V devices provide some additional damping. The specimen

5 with steel devices exhibits some strength degradation. This loss can be traced to the fact that the steel dissipators will undergo plastic deformation in tension and will not recover that deformation

7 in compression in part due to buckling.

Partial buckling of the dissipators also means that less dissipation occurs on subsequent loading cycles, potentially leading to larger earthquake-induced displacements. More explicitly, only peak cycles receive full dissipation with the mild steel dampers, rather than every cycle regardless of

11 size. The HF2V devices do not exhibit this effect. The hysteresis loops of the specimen that utilizes the HF2V devices are stable, showing no apparent strength degradation on the second cycle of

13 loading for a given drift amplitude.

On larger displacement cycles, the HF2V dampers provided a significantly greater amount of

15 hysteretic energy dissipation. This result can be seen in Figure 9, where an additional two cycles to $3 \%$ drift reveal a markedly large change in response. The specimen exhibited some drop in 17 strength during reloading to the previous peak, but no overall capacity was lost.

This loss can be seen more clearly in the force-displacement response during testing of the

19 HF2V devices, which is shown in Figure 10. Before the specimen reached a drift of 3\%, the devices behaved essentially in an elastic manner. At 3\% drift, the devices fully engaged and yielded,

21 with the shaft moving approximately $3.5 \mathrm{~mm}$. Upon subsequent loading and unloading, the device exhibits an 'elasto-plastic' type of response, with slight 'pinching' at zero force. This pinching can be attributed to take-up within the connecting threaded elements of the device. The shaft does not return to its initial position, but upon completion of the test remains about $1.5 \mathrm{~mm}$ from its initial position, due to take-up and mount flexibility.

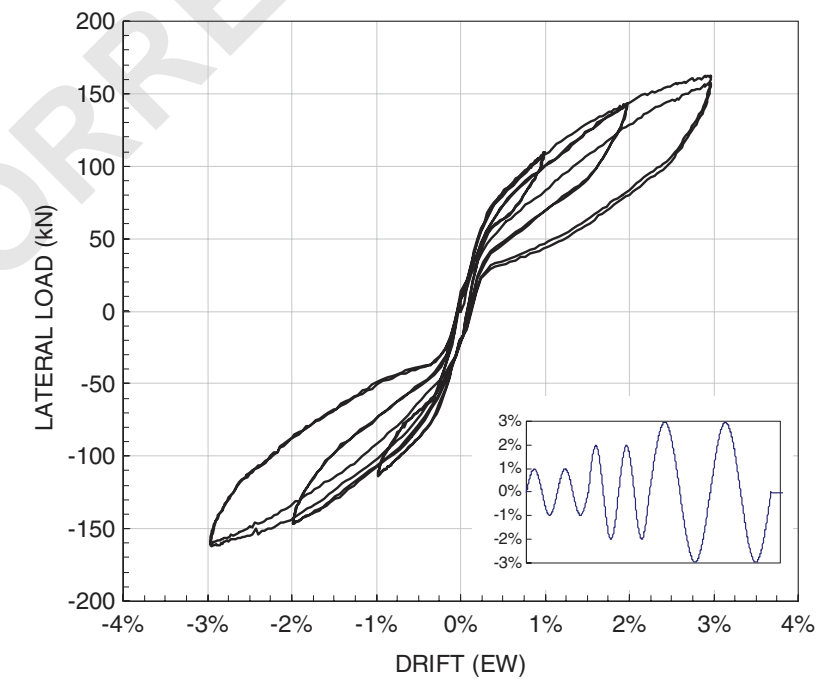

Figure 9. Response of the specimen with HF2V dampers to $3 \%$ drift (inset: quasi-static loading regime). 


\section{EQE 830}

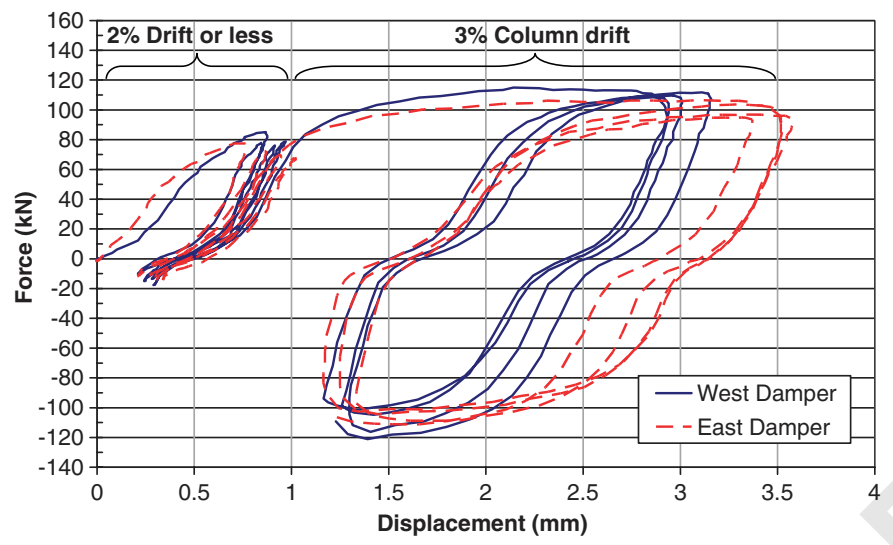

Figure 10. In-service force-displacement response of the HF2V devices.

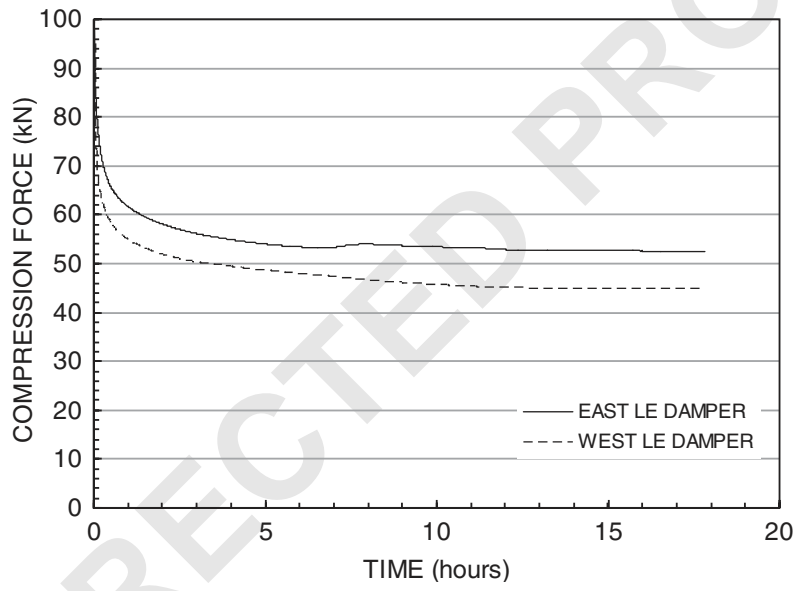

Figure 11. Damper force over time.

1 After testing, the residual compression force in the HF2V damper and anchor shaft was approximately $90 \mathrm{kN}$. A logarithmic decrement of force occurred over time, as shown in Figure 11.

3 Within the first $5 \mathrm{~h}$ the force in the devices had dropped by some $50 \mathrm{kN}$-about $45 \%$ of the peak compression force. This is a clear advantage of the lead-extrusion dampers over the steel fuse bars.

5 More specifically, as well as remaining completely damage-free and operating efficiently for every cycle, the residual compressive force creeps out of the devices, leading to complete self-centring

7 of the joint. Note that the low residual forces in Figure 11 are well within the $(\lambda>1.0)$ re-centring capability of the joint, as well.

\section{Corner joint}

As noted in the previous section, after the initial testing, the east beam was removed and its damper

11 was relocated to the west beam, doubling the beam's energy dissipation capacity. Figure 12 presents the response of the specimen with and without the dampers, subjected to fully reversed loading 


\section{EQE 830}

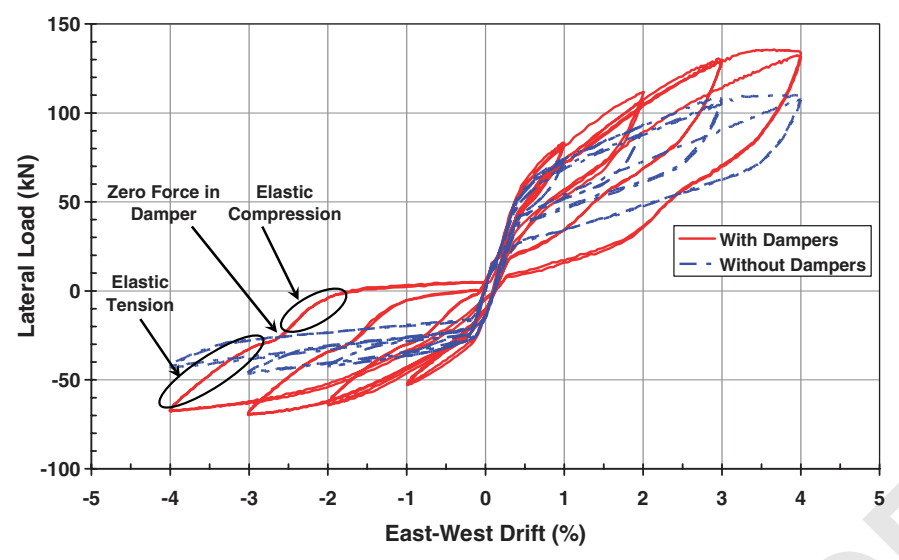

Figure 12. Response of corner joint specimen QS testing to $4 \%$ drift.

1 cycle out to $4 \%$ drift. The asymmetry of the force-drift response is due to the eccentricity of the tendon with respect to the beam mid-depth. Although this asymmetry has always been present, the hysteresis loops presented in Figures 8 and 9 do not show this asymmetry, as the presence of both the east and west beams balanced out this effect. More specifically, although the forces at each interface were asymmetrical, the west interface was undergoing the opposite joint rotation to the east interface, resulting in overall symmetry of the hysteresis loops. The removal of the east

7 beam removed this cancellation, resulting in the asymmetry seen in Figure 12.

It is apparent that the specimen exhibits significantly more energy dissipation when compared 9 with previous tests in Figures 8 and 9, as was expected due to the increased damping forces. However, re-centring was still apparent despite $\lambda<1.0$ for negative direction loading, with smaller 11 tendon eccentricity. Finally, the residual displacements were negligible.

Some pinching, indicated as localized 'flattening' in the hysteresis loop, was observed during

13 the unloading phase. This phenomenon is attributed to minor take-up within the threaded anchor rods, which occurs when the rod forces change from tension to compression. This phenomenon was confirmed by the load cell readings, indicating that this behaviour coincided with zero load in the devices.

17 Interestingly, the area enclosed within the hysteresis loops for the joint without the dampers shows a large disparity between the two directions. Again, this phenomenon can be traced back

19 to the tendon profile. The inherent hysteresis for the joint without dampers is primarily related to the well-known friction effects that exist in draped tendons, in this case between the prestressing

21 tendons and the PVC ducts in which they are contained. The bent tendon profile results in notable friction between the tendon and PVC ducts, as the tendon undergoes deformation during gap

23 opening. The drape (curve) of the tendon naturally leads to higher friction for gap opening in one direction than the other.

25 Under positive loading when the drifts exceeded $+3.4 \%$, some minor strength degradation was observed as a result of yielding of the reduced-section thread bars. This is not considered to be

27 a bad feature, rather it was intended, by design. If substantial yielding occurs when drift exceeds say $5 \%$, then the connecting reduced-section thread-bars can be replaced.

29 Finally, to quantify the relative amounts of damping provided by the jointed connection, without any supplemental damping devices, with yielding steel fuse bars, and with the HF2V dampers, 
Table I. Energy dissipated for different joint configurations (J).

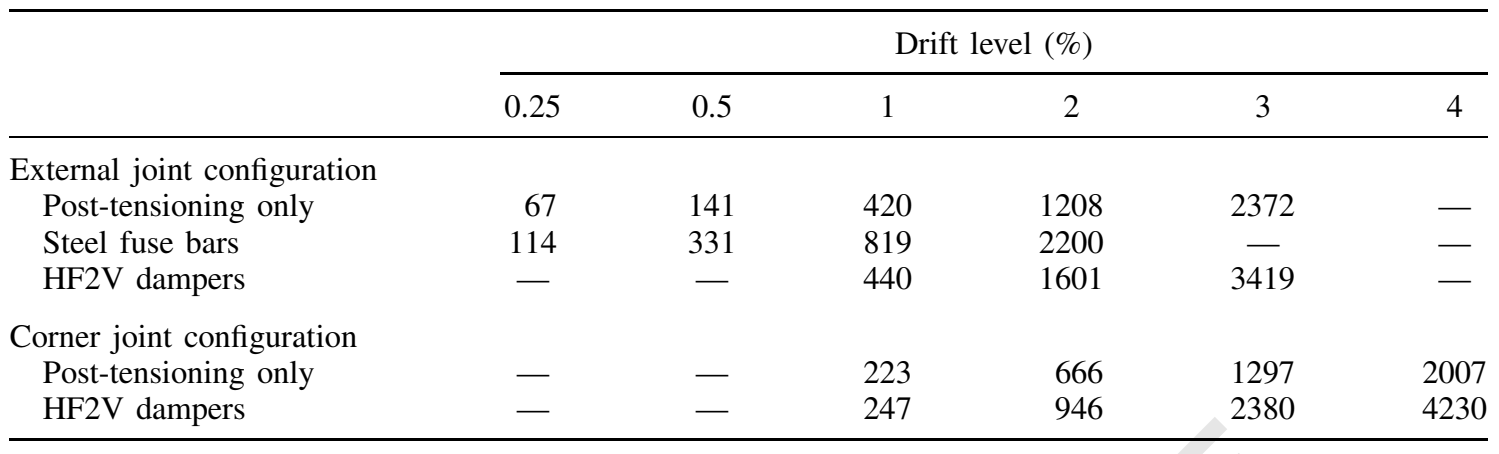

Note: The steel fuse bars are not tested in the corner joint configuration, and the HF2V dampers are at a minimum capacity for the size of the connection for the external joint set-up.

1 the areas enclosed within the hysteresis loops were numerically integrated. These areas represent the energy dissipated. The results of this integration are presented in Table I, where the values

3 represent the average enclosed area across four peaks to each drift level, resulting from two fully reversed sinusoidal loading patterns.

5 It should be noted that since the figures are an average over four cycles, the values do not necessarily represent a stable and repeatable amount of energy dissipation, and the large dissipation

7 on the first cycle may not be matched on subsequent cycles. In particular, at $2 \%$ drift levels, an overall average of $2200 \mathrm{~J}$ is dissipated by the joint with steel fuses, compared with $1600 \mathrm{~J}$ for

9 the joint with HF2V dampers. However, the much larger dissipation for the steel is only due to the large dissipation on the initial cycles, with the third and fourth cycles having dissipation of

11 approximately $1800 \mathrm{~J}$, bringing it much closer to the energy dissipated by the joint with the HF2V dampers. Moreover, the steel fuses were not tested in uni-directional testing up to 3 or $4 \%$ drift;

13 hence, comparisons could not be made at larger column drifts where the HF2V dampers provided better dissipation.

15 The larger dissipation from the HF2V dampers at higher drifts can be attributed to the take-up or slackness in the connecting elements. The corner joint results show that at $1 \%$ column drift,

17 the HF2V dampers increase the inherent hysteretic damping of the joint by approximately $11 \%$, whereas the increase over the undamped joint becomes 42,84 , and $110 \%$ at column drifts of

192,3 , and 4\%, respectively. The lack of contribution at the lower drift levels could be mitigated by careful design of the connecting elements to eliminate flexibility and take-up/slackness.

Overall, the energy dissipation provided by the HF2V dampers is somewhat underrepresented due to both the conservative size of the dampers chosen and the sources of flexibility. Much

23 larger dampers could be provided in the external joint configuration while maintaining static joint re-centring ability, as demonstrated by the corner joint configuration. Hence, the highly repeatable

25 (cycle-to-cycle) HF2V device results could be readily improved by increasing the device force capacity, thus presenting a different comparison to the steel fuse bars than that seen in Table I.

\section{DISCUSSION}

The performance of the specimen met the two primary performance objectives: (i) the dissipation of considerable energy by the supplemental HF2V devices and (ii) with no structural damage. 


\section{EQE 830}

1 This proof-of-concept experiment has validated the efficacy of incorporating HF2 V devices into a beam-column joint to reliably dissipate seismic energy. Although the devices were slow to 'engage'

3 and take full effect at small drifts due to some mount flexibility, at higher drifts it was found that the specimen exhibited much larger hysteresis loops and therefore absorbed considerably more

5 energy than with the mild steel devices, which buckled on compression. The flexibility issue could be easily mitigated in design by selecting a larger shaft diameter and/or connecting rods with

7 lower levels of stress during operation. The ability of the extrusion-based devices to dissipate the residual compressive force over time through creep effects means that essentially zero moment 9 exists at zero drift ensuring full re-centring capability of the structure. Moreover, no maintenance of the damping system following an earthquake is expected to be needed.

As noted previously, the devices were slow to 'engage', as evidenced by the stark difference in hysteretic energy dissipation shown in Figures 8 and 9, between 2 and 3\% column drift. This

13 lag was traced (in part) to the anchoring system utilized. Given the properties of the anchor rod, its elongation at the yield force of the damper $(120 \mathrm{kN})$ would be approximately $2.5 \mathrm{~mm}$. Given a

15 column drift of $2 \%$, which corresponds to a connection rotation of about $0.015 \mathrm{rad}$, the maximum expected gap opening at the location of the extrusion dampers is $4.5 \mathrm{~mm}$. The elongation of the

17 rod would account for more than half this amount, thus seriously reducing the effectiveness of the device. This effect is magnified by the fact that each connecting element (the coupler, nuts, anchor

19 plates) exhibits some degree of take-up, which must also be accommodated before the full yield force of the dissipator can be reached. Given the elastic stiffness of the damper $(200 \mathrm{kN} / \mathrm{mm})$,

21 such effects can be notably detrimental to the full effectiveness of the dampers' contribution to the joint. This effect can be best further explained looking at the system based on strain energy. For

23 maximum energy dissipation, it is desirable to have the minimum amount of elastic strain energy in the connecting elements, so that the largest displacement is applied directly to the dampers, 25 which will in turn lead to the greatest effectiveness of the HF2V devices in absorbing energy.

The lag effect of damper mount and connecting rod flexibility is also the reason why the 27 specimen exhibited minor strength degradation on secondary cycles. At the completion of a cycle, the damper and its connecting elements would be in compression. At the onset of a reversed cycle,

29 the anchor rods need to first transition from a fully elastic compression state to an elongation in tension, thus requiring even greater displacements of the joint for yielding of the dissipation device

31 to occur. This effect may be considerably reduced if the damper and its anchorage elements are prestressed, thus eliminating any sources of flexibility and take-up in the system. Other solutions

33 include lower stresses in all elements connecting to the HF2V devices, if warranted, or embedded devices within the concrete members.

35 In future efforts, care should be taken when designing the dissipator anchorage, with specific attention given to eliminating any slackness or take-up within the system. During initial testing

37 of the extrusion dampers (prior to mounting them on the specimen) and from previous published work [16] it was found that the peak yield force of the devices was weakly velocity dependent,

39 with a velocity exponent in the range of $0.11-0.15$. This effect may be beneficial, as under very rapid displacements, such as would be expected in a large earthquake, the device would provide

41 additional damping to the structure. This allows the dampers to provide a force higher than the restoring force from prestress, while still allowing the connection to re-centre upon unloading, 43 unlike sacrificial steel-yielding bars/devices. However, if the increase is significant, it is possible that the increased force is detrimental to the weak beam-strong column, capacity design principles

45 utilized here. Therefore, the damper velocity characteristics should be utilized to predict force levels for the dampers under full dynamic loading, and these forces incorporated into the capacity 


\section{EQE 830}

PERFORMANCE OF A DAMAGE-PROTECTED BEAM-COLUMN SUBASSEMBLY

1 design procedures. In particular, careful design can account for, and eliminate, any detrimental effects relating to this velocity dependence. More specifically, careful damper design, based on 3 well-defined design equations [13], along with careful connection design, will readily provide an optimal outcome.

This study has presented a proof-of-concept experimental investigation. Compact high force-to-

\section{CONCLUSIONS}

volume (HF2V) devices capable of being fitted directly into a structural connection, an alternative to mild steel energy dissipation devices, were mounted externally across a beam-column joint. Based on the results of this study, the following conclusions can be drawn:

1. It was demonstrated through QS testing that the HF2V dampers could provide a level of energy dissipation comparable to, or in excess of, mild steel devices designed for the same yield force at low drifts. Larger drifts saw significantly increased energy dissipation from the extrusion dampers. Subsequent smaller motions received full dissipation, which would not occur with yielding dissipators.

2. HF2V extrusion dampers offer an attractive alternative to mild steel energy dissipation devices. These devices do not suffer from low-cycle fatigue and the force in the devices creeps back towards zero upon unloading. Therefore, they do not need any maintenance following an earthquake and could be mounted internally. The ability of the device force to creep out over time ensures that self-centring of the structure is maintained following an earthquake.

3. The stiffness of device mounts and connecting elements is an important consideration. Since gap opening is generally $5-10 \mathrm{~mm}$, stiffness plays an important role in the effectiveness of supplemental energy dissipation. Care should be taken when designing the anchorage for these devices. Prestressing the devices will help to eliminate take-up in the system and ensure a more optimal solution.

\section{REFERENCES}

1. Priestley MJN, Sritharan S, Conley JR, Pampanin S. Preliminary results and conclusions from the PRESSS five-story precast concrete test building. PCI Journal 1999; 44(6):42-67.

2. Ajrab JJ, Pekcan G, Mander JB. Rocking wall-frame structures with supplemental tendon systems. Journal of Structural Engineering 2004; 130(6):895-903. DOI: 10.1061/(ASCE)0733-9445(2004)130:6(895).

3. Mander JB. Beyond ductility: the quest goes on. Bulletin of the New Zealand Society for Earthquake Engineering 2004; 37(1):35-44.

4. Mander JB, Cheng C-T. Seismic resistance of bridge piers based on damage avoidance design. Technical Report NCEER-97-0014, U.S. National Center for Earthquake Engineering Research (NCEER), Department of Civil and Environmental Engineering, State University of New York at Buffalo, Buffalo, U.S.A., 1997.

5. Bradley BA, Dhakal RP, Mander JB, Li L. Experimental multi-level seismic performance assessment of 3D RC frame designed for damage avoidance. Earthquake Engineering and Structural Dynamics 2008; 37(1):1-20. DOI: $10.1002 /$ eqe. 741 .

6. Holden T, Restrepo J, Mander JB. Seismic performance of precast reinforced and prestressed concrete walls. Journal of Structural Engineering 2003; 129(3):286-296. DOI: 10.1061/(ASCE)0733-9445(2003)129:3(286).

7. Solberg KM, Mashiko N, Mander JB, Dhakal RP. Performance of a damage protected highway bridge pier subjected to bi-directional earthquake attack. Journal of Structural Engineering (ASCE), in press.

8. Cheok GS, Lew HS. Performance of precast concrete beam-to-column connections subject to cyclic loading. PCI Journal 1991; 36(3):56-67. 


\section{EQE 830}

1 9. Priestley MJN, Tao J. Seismic response of precast prestressed concrete frames with partially debonded tendons. PCI Journal 1993; 38(1):58-69.

3 10. Stanton J, Stone WC, Cheok GS. Hybrid reinforced precast frame for seismic regions. PCI Journal 1997; 42(2):20-32.

5 11. Dhakal RP, Maekawa K. Path-dependent cyclic stress-strain relationship of reinforcing bar including buckling. Engineering Structures 2002; 24(11):1383-1396. DOI: 10.1016/S0141-0296(02)00080-9.

7 12. Amaris A, Pampanin S, Palmero A. Uni and bi-directional quasi-static tests on alternative hybrid precast beamcolumn joint subassemblies. Presented at New Zealand Society for Earthquake Engineering Annual Conference (NZSEE06), Napier, New Zealand, 2006.

13. Rodgers GW, Chase JG, Mander JB, Leach NC, Denmead CS. Experimental development, tradeoff analysis and design implementation of high force-to-volume damping technology. Bulletin of the New Zealand Society for Earthquake Engineering 2007; 40(2):35-48.

13 14. Rodgers GW, Mander JB, Chase JG, Dhakal RP, Leach NC, Denmead CS. Spectral analysis and design approach for high force-to-volume extrusion damper-based structural energy dissipation. Earthquake Engineering and Structural Dynamics 2008; 37(2):207-223. DOI: 10.1002/eqe.752.

15. Robinson WH, Greenbank LR. Extrusion energy absorber suitable for the protection of structures during an earthquake. Earthquake Engineering and Structural Dynamics 1976; 4(3):251-259. DOI: 10.1002/eqe. 4290040306.

19 16. Cousins WJ, Porritt TE. Improvements to lead-extrusion damper technology. Bulletin of the New Zealand National Society for Earthquake Engineering 1993; 26(3):342-348.

21 17. Li L, Mander JB, Dhakal RP. Bi-directional cyclic loading experiment on a 3-D beam-column joint designed for damage avoidance. Journal of Structural Engineering (ASCE) 2008; accepted.

23 18. Solberg KM, Dhakal RP, Bradley BA, Mander JB, Li L. Seismic performance of damage-protected beam-column joints. ACI Structural Journal 2008; 105(2):205-214. 
John Wiley \& Sons Ltd

The Atrium, Southern Gate, Chichester West, Sussex PO19 8SQ

While preparing this paper/manuscript for typesetting, the following queries have arisen

\begin{tabular}{|c|c|c|c|c|}
\hline $\begin{array}{c}\text { Query } \\
\text { No. }\end{array}$ & $\begin{array}{c}\text { Proof } \\
\text { Page/line } \\
\text { no }\end{array}$ & & \multicolumn{1}{|c|}{ Details required } & Authors response \\
\hline \multirow{2}{*}{1} & General & $\begin{array}{l}\text { The word “dissipater" has been changed to “dissipator" throughout } \\
\text { the article, please check. }\end{array}$ & \\
\hline 2 & References & Please provide the year and DOI number for Ref. [7]. & \\
\hline & & & \\
\hline & & & \\
\hline & & & \\
\hline & & & \\
\hline & & & \\
\hline & & & \\
\hline & & & \\
\hline
\end{tabular}


(the "Contribution") written by

(the "Contributor") for publication in...

(the "Journal) published by John Wiley \& Sons Ltd ("Wiley").

In order to expedite the publishing process and enable Wiley to disseminate your work to the fullest extent, we need to have this Copyright Transfer Agreement signed and returned to us with the submission of your manuscript. If the Contribution is not accepted for publication this Agreement shall be null and void.

\section{A. COPYRight}

1. The Contributor assigns to Wiley, during the full term of copyright and any extensions or renewals of that term, all copyright in and to the Contribution, including but not limited to the right to publish, republish, transmit, sell, distribute and otherwise use the Contribution and the material contained therein in electronic and print editions of the Journal and in derivative works throughout the world, in all languages and in all media of expression now known or later developed, and to license or permit others to do so.

2. Reproduction, posting, transmission or other distribution or use of the Contribution or any material contained therein, in any medium as permitted hereunder, requires a citation to the Journal and an appropriate credit to Wiley as Publisher, suitable in form and content as follows: (Title of Article, Author, Journal Title and Volume/Issue Copyright $($ C [year] John Wiley \& Sons Ltd or copyright owner as specified in the Journal.)

\section{B. RETAINED RightS}

Notwithstanding the above, the Contributor or, if applicable, the Contributor's Employer, retains all proprietary rights other than copyright, such as patent rights, in any process, procedure or article of manufacture described in the Contribution, and the right to make oral presentations of material from the Contribution.

\section{OTHER Rights OF CONTRIBUTOR}

Wiley grants back to the Contributor the following:

1. The right to share with colleagues print or electronic "preprints" of the unpublished Contribution, in form and content as accepted by Wiley for publication in the Journal. Such preprints may be posted as electronic files on the Contributor's own website for personal or professional use, or on the Contributor's internal university or corporate networks/intranet, or secure external website at the Contributor's institution, but not for commercial sale or for any systematic external distribution by a third party (eg: a listserver or database connected to a public access server). Prior to publication, the Contributor must include the following notice on the preprint: "This is a preprint of an article accepted for publication in [Journal title] Copyright (C) (year) (copyright owner as specified in the Journal)". After publication of the Contribution by Wiley, the preprint notice should be amended to read as follows: "This is a preprint of an article published in [include the complete citation information for the final version of the Contribution as published in the print edition of the Journal]" and should provide an electronic link to the Journal's WWW site, located at the following Wiley URL: http://www.interscience.wiley.com/. The Contributor agrees not to update the preprint or replace it with the published version of the Contribution.

2. The right, without charge, to photocopy or to transmit on-line or to download, print out and distribute to a colleague a copy of the published Contribution in whole or in part, for the Contributor's personal or professional use, for the advancement of scholarly or scientific research or study, or for corporate informational purposes in accordance with paragraph D2 below.

3. The right to republish, without charge, in print format, all or part of the material from the published Contribution in a book written or edited by the Contributor.

4. The right to use selected figures and tables, and selected text (up to 250 words) from the Contribution, for the Contributor's own teaching purposes, or for incorporation within another work by the Contributor that is made part of an edited work published (in print or electronic format) by a third party, or for presentation in electronic format on an internal computer network or external website of the Contributor or the Contributor's employer. The abstract shall not be included as part of such selected text.

5. The right to include the Contribution in a compilation for classroom use (course packs) to be distributed to students at the Contributor's institution free of charge or to be stored in electronic format in datarooms for access by students at the Contributor's institution as part of their course work (sometimes called "electronic reserve rooms") and for in-house training programmes at the Contributor's employer.

\section{CONTRIBUTIONS OWNED BY EMPLOYER}

1. If the Contribution was written by the Contributor in the course of the Contributor's employment (as a "work-made-for-hire" in the course of employment), the Contribution is owned by the company/employer which must sign this Agreement (in addition to the Contributor's signature), in the space provided below. In such case, the company/employer hereby assigns to Wiley, during the full term of copyright, all copyright in and to the Contribution for the full term of copyright throughout the world as specified in paragraph A above.

2. In addition to the rights specified as retained in paragraph $\mathrm{B}$ above and the rights granted back to the Contributor pursuant to paragraph $\mathrm{C}$ above, Wiley hereby grants back, without charge, to such company/employer, its subsidiaries and divisions, the right to make copies of and distribute the published Contribution internally in print format or electronically on the Company's internal network. Upon payment of the Publisher's reprint fee, the institution may distribute (but not re-sell) print copies of the published Contribution externally. Although copies so made shall not be available for individual re-sale, they may be included by the company/employer as part of an information package included with software or other products offered for sale or license. Posting of the published Contribution by the institution on a public access website may only be done with Wiley's written permission, and payment of any applicable fee(s). 


\section{E. GOVERNMENT CONTRACTS}

In the case of a Contribution prepared under US Government contract or grant, the US Government may reproduce, without charge, all or portions of the Contribution and may authorise others to do so, for official US Government purposes only, if the US Government contract or grant so requires. (Government Employees: see note at end.)

\section{F. COPYRight NOTICE}

The Contributor and the company/employer agree that any and all copies of the Contribution or any part thereof distributed or posted by them in print or electronic format as permitted herein will include the notice of copyright as stipulated in the Journal and a full citation to the Journal as published by Wiley.

\section{G. CONTRIBUtor's REPRESENTATIONS}

The Contributor represents that the Contribution is the Contributor's original work. If the Contribution was prepared jointly, the Contributor agrees to inform the coContributors of the terms of this Agreement and to obtain their signature(s) to this Agreement or their written permission to sign on their behalf. The Contribution is submitted only to this Journal and has not been published before, except for "preprints" as permitted above. (If excerpts from copyrighted works owned by third parties are included, the Contributor will obtain written permission from the copyright owners for all uses as set forth in Wiley's permissions form or in the Journal's Instructions for Contributors, and show credit to the sources in the Contribution.) The Contributor also warrants that the Contribution contains no libelous or unlawful statements, does not infringe on the right or privacy of others, or contain material or instructions that might cause harm or injury.

Tick one box and fill in the appropriate section before returning the original signed copy to the Publisher

\section{Contributor-owned work}

Contributor's signature Date

Type or print name and title

Co-contributor's signature Date

Type or print name and title

\section{Attach additional signature page as necessary}

Company/Institution-owned work (made-for-

hire in the course of employment)

Contributor's signature

Type or print name and title

Company or Institution

(Employer-for Hire)

Authorised signature of Employer

Type or print name and title

\section{US Government work}

Note to US Government Employees

A Contribution prepared by a US federal government employee as part of the employee's official duties, or which is an official US Government publication is called a "US Government work", and is in the public domain in the United States. In such case, the employee may cross out paragraph A1 but must sign and return this Agreement. If the Contribution was not prepared as part of the employee's duties or is not an official US Government publication, it is not a US Government work.

\section{UK Government work (Crown Copyright)}

Note to UK Government Employees

The rights in a Contribution by an employee of a UK Government department, agency or other Crown body as part of his/her official duties, or which is an official government publication, belong to the Crown. In such case, the Publisher will forward the relevant form to the Employee for signature. 


\section{WILEY AUTHOR DISCOUNT CARD}

As a highly valued contributor to Wiley's publications, we would like to show our appreciation to you by offering a unique $\mathbf{2 5 \%}$ discount off the published price of any of our books*.

To take advantage of this offer, all you need to do is apply for the Wiley Author Discount Card by completing the attached form and returning it to us at the following address:

The Database Group

John Wiley \& Sons Ltd

The Atrium

Southern Gate

Chichester

West Sussex PO19 8SQ

UK

In the meantime, whenever you order books direct from us, simply quote promotional code S001W to take advantage of the $25 \%$ discount.

The newest and quickest way to order your books from us is via our new European website at:

\section{http://www.wileyeurope.com}

Key benefits to using the site and ordering online include:

- $\quad$ Real-time SECURE on-line ordering

- The most up-to-date search functionality to make browsing the catalogue easier

- Dedicated Author resource centre

- E-mail a friend

- Easy to use navigation

- Regular special offers

- $\quad$ Sign up for subject orientated e-mail alerts

So take advantage of this great offer, return your completed form today to receive your discount card.

Yours sincerely,

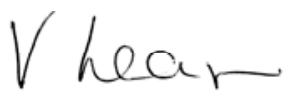

Verity Leaver

E-marketing and Database Manager

This offer is exclusive to Wiley Authors, Editors, Contributors and Editorial Board Members in acquiring books (excluding encyclopaedias and major reference works) for their personal use. There must be no resale through any channel. The offer is subject to stock availability and cannot be applied retrospectively. This entitlement cannot be used in conjunction with any other special offer. Wiley reserves the right to amend the terms of the offer at any time. 


\section{REGISTRATION FORM FOR 25\% BOOK DISCOUNT CARD}

To enjoy your special discount, tell us your areas of interest and you will receive relevant catalogues or leaflets from which to select your books. Please indicate your specific subject areas below.

\section{Accounting}

- Public

- Corporate

\section{Chemistry}

- Analytical

- Industrial/Safety

- Organic

- Inorganic

- Polymer

- Spectroscopy

Encyclopedia/Reference

- Business/Finance

- Life Sciences

- Medical Sciences

- Physical Sciences

- Technology

\section{Earth \& Environmental Science}

Hospitality

\section{Genetics}

- Bioinformatics/Computational Biology

- Proteomics

- Genomics

- Gene Mapping

- Clinical Genetics

\section{Medical Science}

- Cardiovascular

- Diabetes

- Endocrinology

- Imaging

- Obstetrics/Gynaecology

- Oncology

- Pharmacology

- Psychiatry

\section{Architecture}

Business/Management

Computer Science

- Database/Data Warehouse

- Internet Business

- Networking

- Programming/Software

Development

- Object Technology

Engineering

- Civil

- Communications Technology

- Electronic

- Environmental

- Industrial

- Mechanical

Finance/Investing

- Economics

- Institutional

- Personal Finance

Life Science

Landscape Architecture

Mathematics/Statistics

Manufacturing

Material Science

Psychology

- Clinical

- Forensic

- Social \& Personality

- Health \& Sport

- Cognitive

- Organizational

- Developmental and Special Ed

- Child Welfare

- Self-Help

Physics/Physical Science 
SIGNATURE:

\section{PLEASE COMPLETE THE FOLLOWING DETAILS IN BLOCK CAPITALS:}

TITLE AND NAME: (e.g. Mr, Mrs, Dr)

JOB TITLE:

DEPARTMENT:

COMPANY/INSTITUTION:

ADDRESS:

TOWN/CITY:

COUNTY/STATE:

COUNTRY:

POSTCODE/ZIP CODE:

DAYTIME TEL:

FAX:

E-MAIL:

YOUR PERSONAL DATA

We, John Wiley \& Sons Ltd, will use the information you have provided to fulfil your request. In addition, we would like to:

1. Use your information to keep you informed by post, e-mail or telephone of titles and offers of interest to you and available from us or other Wiley Group companies worldwide, and may supply your details to members of the Wiley Group for this purpose.

[ ] Please tick the box if you do not wish to receive this information

2. Share your information with other carefully selected companies so that they may contact you by post, fax or e-mail with details of titles and offers that may be of interest to you.

[ ] Please tick the box if you do not wish to receive this information.

If, at any time, you wish to stop receiving information, please contact the Database Group (databasegroup@wiley.co.uk) at John Wiley \& Sons Ltd, The Atrium, Southern Gate, Chichester, West Sussex PO19 8SQ, UK.

\section{E-MAIL ALERTING SERVICE}

We offer an information service on our product ranges via e-mail. If you do not wish to receive information and offers from John Wiley companies worldwide via e-mail, please tick the box [ ].

This offer is exclusive to Wiley Authors, Editors, Contributors and Editorial Board Members in acquiring books (excluding encyclopaedias and major reference works) for their personal use. There should be no resale through any channel. The offer is subject to stock availability and may not be applied retrospectively. This entitlement cannot be used in conjunction with any other special offer. Wiley reserves the right to vary the terms of the offer at any time.

Ref: S001W 